\title{
Obesity as a susceptibility factor to indoor particulate matter health effects in COPD
}

\author{
Meredith C. McCormack ${ }^{1,2}$, Andrew J. Belli ${ }^{1}$, Deepak A. Kaji ${ }^{1}$, \\ Elizabeth C. Matsui ${ }^{3}$, Emily P. Brigham ${ }^{1}$, Roger D. Peng ${ }^{4}$, Cortlandt Sellers ${ }^{1}$, \\ D’Ann L. Williams ${ }^{2}$, Gregory B. Diette ${ }^{1,2}$, Patrick N. Breysse ${ }^{2}$ and \\ Nadia N. Hansel ${ }^{1,2}$
}

Affiliations: 'Dept of Medicine, Division of Pulmonary and Critical Care, Johns Hopkins University School of Medicine, Baltimore, MD, USA. ${ }^{2}$ Dept of Environmental Health Sciences, Johns Hopkins Bloomberg School of Public Health, Baltimore, MD, USA. ${ }^{3}$ Dept of Pediatrics, Division of Allergy and Immunology, Johns Hopkins University School of Medicine, Baltimore, MD, USA. ${ }^{4}$ Dept of Biostatistics, Johns Hopkins Bloomberg School of Public Health, Baltimore, MD, USA.

Correspondence: Meredith C. McCormack, Pulmonary and Critical Care Medicine, Johns Hopkins University, 1830 East Monument Street, 5th Floor, Baltimore, MD 21205, USA.

E-mail: Mmccor16ajhmi.edu

ABSTRACT Our goal was to investigate whether obesity increases susceptibility to the adverse effects of indoor particulate matter on respiratory morbidity among individuals with chronic obstructive pulmonary disease (COPD).

Participants with COPD were studied at baseline, 3 and 6 months. Obesity was defined as a body mass index $\geqslant 30 \mathrm{~kg} \cdot \mathrm{m}^{-2}$. At each time point, indoor air was sampled for 5-7 days and particulate matter (PM) with an aerodynamic size $\leqslant 2.5 \mu \mathrm{m}(\mathrm{PM} 2.5)$ and $2.5-10 \mu \mathrm{m}$ (PM2.5-10) was measured. Respiratory symptoms, health status, rescue medication use, exacerbations, blood biomarkers and exhaled nitric oxide were assessed simultaneously.

Of the 84 participants enrolled, 56\% were obese and all were former smokers with moderate-to-severe COPD. Obese participants tended to have less severe disease as assessed by Global Initiative for Chronic Obstructive Pulmonary Disease stage and fewer pack-years of smoking. There was evidence that obesity modified the effects of indoor PM on COPD respiratory outcomes. Increases in PM2.5 and PM2.5-10 were associated with greater increases in nocturnal symptoms, dyspnoea and rescue medication use among obese versus non-obese participants. The impact of indoor PM on exacerbations, respiratory status and wheeze also tended to be greater among obese versus non-obese participants, as were differences in airway and systemic inflammatory responses to indoor PM.

We found evidence that obesity was associated with exaggerated responses to indoor fine and coarse PM exposure among individuals with COPD.

@ERSpublications

Obesity may increase susceptibility to adverse respiratory effects of indoor particulate matter exposure among those with COPD http://ow.ly/DYf6T ES018176, F32 HL 120396). Funding information for this article has been deposited with FundRef.

Conflict of interest: Disclosures can be found alongside the online version of this article at erj.ersjournals.com

Copyright OERS 2015 


\section{Introduction}

Chronic obstructive pulmonary disease (COPD) is currently the fifth leading cause of death worldwide and is expected to increase in prevalence during the next few decades [1]. The majority of COPD is caused by environmental factors [2]. While tobacco smoke is the primary causal factor in developed countries, ongoing exposure to airborne pollutants worsens COPD morbidity. Exposure to outdoor particulate matter (PM) has been linked to increases in COPD hospitalisations and mortality [3, 4]. Indoor PM has unique sources, such as household cooking and smoking, as well as penetration of outdoor air into the indoor environment [5]. Indoor air quality is highly relevant as individuals in developed countries spend the majority of their time indoors and indoor air quality may be more easily modified at the individual level [6]. We have recently shown that even relatively low concentrations of indoor PM are associated with increased respiratory morbidity among patients with COPD [7].

In addition to environmental factors, individual characteristics, such as age, sex, comorbid illness and genetics, have been linked to COPD outcomes. Body mass has also been associated with COPD outcomes and the concept of the obesity paradox in COPD has focused largely on the increased risk of death among those with low body mass, especially among those with severe disease [8]. However, there has been more recent interest in the consequences of obesity as the prevalence of obesity among adults in the USA has increased significantly in the past 50 years, with nearly a third of adult Americans estimated to be obese in 2008 [9]. Obesity has been associated with worse COPD outcomes, including increased dyspnoea, wheeze and worse quality of life [10-12]. Several recent studies suggest that obesity may confer increased susceptibility to the respiratory effects of air pollution, specifically PM exposure [13-15]. For example, a recent study conducted in children with asthma showed that PM with an aerodynamic size $\leqslant 2.5 \mu \mathrm{m}$ (PM2.5) concentrations were more strongly associated with respiratory symptoms among overweight and obese children with persistent asthma when compared with those who were normal weight [15]. In addition to the direct effects of obesity on COPD, it is plausible that overweight or obese individuals with COPD might also have increased susceptibility to the adverse effects of PM on respiratory status [16-18]. There is a need for more evidence to define the role of obesity as a susceptibility factor for air pollutant respiratory effects and, to our knowledge, this has never been investigated in COPD. The goal of this analysis was to investigate whether obese individuals with moderate-to-severe COPD were more susceptible to the adverse effects of PM on respiratory morbidity than non-obese individuals.

\section{Methods}

\section{Participant recruitment}

Participants provided written informed consent and the Johns Hopkins Medical Institutional Review Board approved the protocol. Participants and methods were described previously [7]. Briefly, participants were former smokers with COPD recruited from the Baltimore area. Inclusion criteria were: 1) age $\geqslant 40$ years, 2) post-bronchodilator forced expiratory volume in $1 \mathrm{~s}$ (FEV1) $\leqslant 80 \%$ predicted, 3) FEV1/forced vital capacity $<70 \%$, and 4) $>10$ pack-years smoking, but having quit smoking $>1$ year prior to enrolment with an exhaled carbon monoxide level $\leqslant 6 \mathrm{ppm}[19]$.

\section{Study design}

Participants were enrolled and studied at baseline, 3 and 6 months. At each time interval, a 1 week home environmental assessment was conducted and at the end of each week participants completed a clinic visit.

\section{In-home air quality and environmental assessment}

A home inspection was conducted by a trained technician at baseline. Air sampling was performed at baseline, 3 and 6 months in the main living area, which was identified as a room other than the bedroom where the participant reported spending the most time. A 1-week monitoring period was chosen to include exposures that may vary by day of the week and to include weekend days. Indoor air sampling for PM2.5 and PM with an aerodynamic size 2.5-10 $\mu \mathrm{m}$ (PM2.5-10) was conducted as described previously $[7,20]$. In order to perform a sensitivity analysis including outdoor temperature and humidity, data were obtained from the National Oceanic and Atmospheric Administration (NOAA) National Climatic Data Center (Asheville, NC, USA). Hourly temperature and humidity data were collected from the Maryland Science Center station (WBAN\# 93784).

\section{Clinic visits}

Participant demographics were ascertained at a baseline clinic visit. Education was used as a surrogate for socioeconomic status as many participants were older and no longer worked, making annual household income less reliable. Spirometry was performed according to American Thoracic Society (ATS) criteria and was included in the models as a measure of baseline disease severity [21, 22]. Patients were classified into Global Initiative for Chronic Obstructive Lung Disease (GOLD) stages based on their lung function [23]. 
Atopic status was determined by specific IgE assessment using ImmunoCAP (Phadia, ThermoFisher, USA) for mouse, cockroach, cat, dog and dust mite allergens. A participant was considered atopic if at least one test was at or above the level of detection $\left(0.1 \mathrm{kUA} \cdot \mathrm{L}^{-1}\right)$.

\section{Assessment of weight}

Participant height and weight were measured at each visit using a stadiometer. Body mass index (BMI) (kilogrammes divided by metres squared) was calculated and examined as a continuous and as a categorical variable, according to standard definitions of overweight and obese endorsed by the World Health Organization [24]. Analyses of normal weight $\left(\mathrm{BMI}<25 \mathrm{~kg} \cdot \mathrm{m}^{-2}\right.$ ), overweight (BMI $\geqslant 25$ and $<30 \mathrm{~kg} \cdot \mathrm{m}^{-2}$ ) and obese (BMI $\geqslant 30 \mathrm{~kg} \cdot \mathrm{m}^{-2}$ ) individuals [25] suggested that effects in the overweight group were similar to the normal weight group, but the numbers in each group were small. Normal weight and overweight were, therefore, collapsed into a non-obese category $\left(B M I<30 \mathrm{~kg} \cdot \mathrm{m}^{-2}\right.$ ) in the final analysis and results of non-obese (BMI $<30 \mathrm{~kg} \cdot \mathrm{m}^{-2}$ ) versus obese $\left(\mathrm{BMI} \geqslant 30 \mathrm{~kg} \cdot \mathrm{m}^{-2}\right.$ ) are presented. During the follow-up period, only one participant changed categories between obese and non-obese. This participant had a BMI of $30.2 \mathrm{~kg} \cdot \mathrm{m}^{-2}$ at visit $1,29.7 \mathrm{~kg} \cdot \mathrm{m}^{-2}$ at visit 2 and $30.5 \mathrm{~kg} \cdot \mathrm{m}^{-2}$ at visit 3 . This participant was classified as obese in the analyses and a sensitivity analyses demonstrated that results were not substantially different when this participant was excluded (data not shown).

\section{COPD respiratory outcomes and biomarkers}

Participants completed a daily diary that included frequency of rescue medication use $(0,1,2,3$ or $>4$ times daily) during each environmental monitoring period and responses were averaged for each period. Validated questionnaires were administered at each clinic visit and were taken to represent current respiratory status at the time of the environmental monitoring. Dyspnoea was assessed with the modified Medical Research Council (mMRC) dyspnoea scale [26]. Nocturnal symptoms were assessed with a dichotomous "yes" or "no" response to the statement: "my coughing and breathing disturbs my sleep". St George's Respiratory Questionnaire (SGRQ) [27] with a recall period of 4 weeks was used to assess quality of life. Wheeze in the past 4 weeks was assessed as "almost every day, several days a week, a few days a month, only with respiratory infections, or not at all”. Exacerbations were defined as worsening respiratory symptoms leading to an unscheduled doctor visit, an emergency department visit or hospitalisation in the past 3 months [28]. Presence of cough and sputum was determined using the following questions from the modified ATS-DLD (American Thoracic Society-Division of Lung Disease questionnaire) [29]: "Do you usually have a cough?" and "Do you usually bring up phlegm from your chest" at each visit and was dichotomised to "yes" or "no". Peripheral blood was collected at the clinic visits and was analysed for cell count and differential and fibrinogen (Johns Hopkins Medical Research Laboratory). Serum c-reactive protein was measured by ELISA (ALPCO, Salem, NH, USA), and interleukin (IL)-6, IL-8, tumour necrosis factor- $\alpha$ and interferon- $\gamma$ were measured in serum by 4 -Plex Human Cytokine Assay Ultra-Sensitive Kit (Meso Scale Discovery Company, Rockville, MD, USA), according to the manufacturer's instructions (Johns Hopkins Clinical Research Unit Core Laboratory). $6 \%$ of samples were below the limit of detection for interferon- $\gamma\left(0.41 \mathrm{pg} \cdot \mathrm{mL}^{-1}\right)$ and these were assigned values of half the limit of detection. Exhaled nitric oxide was measured using NIOX Mino (Aerocrine AB, Solna, Sweden) according to American Thoracic Society/European Respiratory Society guidelines [30].

Analysis

Data were assessed for normality using graphical displays and appropriate transformations were made. Descriptive statistics were analysed using Spearman correlations, Chi-squared tests and t-tests, as appropriate. To evaluate the effect of PM on respiratory outcomes, continuous and binary outcomes (i.e. nocturnal symptoms and exacerbations) were analysed using linear and logistic regression models, respectively, with PM included as a continuous predictor. Generalised estimating equations models [31] with an exchangeable correlation structure were used in order to account for the correlation arising from repeated measures. Models were adjusted for age, sex, education, and \% predicted FEV1. Spirometry was included in the models as a measure of baseline disease severity. Adjusting for race, season, atopic status or self-reported diabetes or sleep apnea did not significantly affect results (data not shown), and these variables were not included in final models. To test for effect modification, we created an interaction term between PM and obesity status. We created models stratified by obesity status and assessed qualitative differences in the associations between PM exposure and respiratory outcomes. All analyses were performed with StataSE statistical software, version 11.0 (Stata Corp, College Station, TX, USA). A p-value $<0.05$ was considered statistically significant for main effects and a p-value $<0.10$ was considered statistically significant for interactions $[32,33]$. 


\section{Results}

Participant characteristics and obesity

All participants $(\mathrm{n}=84)$ had moderate or severe COPD with a mean baseline FEV1 \% predicted of $53 \%$ (table 1). Approximately half (56\%) of participants were obese, $25 \%$ were overweight and $19 \%$ were normal weight. At baseline, obese participants were more likely to report nocturnal symptoms ( $36 \%$ versus $14 \% ; \mathrm{p}=0.02$ ) and had higher SGRQ scores, indicating worse respiratory status (43 versus $35 ; \mathrm{p}=0.03$ ) than non-obese participants. However, obese participants tended to have less severe disease when assessed using GOLD criteria. Obese individuals also tended to report more comorbid conditions, such as obstructive sleep apnoea, diabetes and a history of myocardial infarction. Participants' environmental characteristics did not differ by obesity status nor did their time spent indoors. Housing characteristics associated with elevated indoor PM concentrations have been published previously [7]. On average, participants reported spending $92 \%$ of their time indoors, of which $80 \%$ was in their own home, including an average of $7.5 \mathrm{~h}$ a day in the main living area where the monitors were placed. The median (interquartile reange) PM2.5 concentrations for obese and non-obese participants were $9.1 \mu \mathrm{g} \cdot \mathrm{m}^{-3}\left(5.4-14.9 \mu \mathrm{g} \cdot \mathrm{m}^{-3}\right)$ and $8.0 \mu \mathrm{g} \cdot \mathrm{m}^{-3}$ $\left(4.3-15.1 \mu \mathrm{g} \cdot \mathrm{m}^{-3}\right)$, respectively $(\mathrm{p}=0.48)$. The indoor $\mathrm{PM} 2.5-10$ concentrations were also not significantly different between non-obese and obese participants.

\section{Association between indoor pollutant concentrations and respiratory morbidity by obesity}

Indoor PM2.5 was significantly associated with respiratory outcomes among obese individuals, but not among non-obese individuals (table 2 and fig. 1). For example, increasing PM2.5 concentrations were strongly associated with dyspnoea as measured by increased mMRC dyspnoea score among obese participants $(\beta=0.20, p<0.01)$ and were not associated with dyspnoea among non-obese participants $(\beta=-0.01 ; p=0.89)$. Increasing PM2.5 concentrations were also strongly associated with nocturnal symptoms among obese participants $(\mathrm{OR}=1.84 ; \mathrm{p}<0.01)$ compared with non-obese participants $(\mathrm{OR}=0.11 ; \mathrm{p}=0.08)$. Positive associations were also seen between indoor PM2.5 and the frequency of rescue inhaler use, SGRQ scores, and the risk of exacerbations among obese participants (table 2). For non-obese participants, an increase in PM2.5 concentrations was not associated with these respiratory outcomes.

Indoor PM2.5-10 was associated with increases in the risk of nocturnal symptoms and dyspnoea among obese participants, but not among non-obese participants (table 2 and fig. 1). There was also a significant difference in the association between indoor $\mathrm{PM} 2.5-10$ and the need for rescue inhaler use among obese $(\beta=0.33 ; p<0.01)$ compared with non-obese participants $(\beta=-0.13 ; p=0.54)$. Indoor $\mathrm{PM} 2.5$ and PM2.5-10 were not associated with symptoms of cough or phlegm among obese participants or in the overall cohort (data not shown). The addition of weekly average outdoor temperature and humidity to the models for PM2.5 and PM2.5-10 did not meaningfully change the results (data not shown).

\section{Association between indoor pollutant concentrations and inflammation by obesity}

Analysis of inflammatory cytokines and biomarkers of inflammation suggested that obesity status modifies the effect of indoor PM on inflammation. Obesity status modified the effect of indoor PM2.5 on peripheral eosinophil count, peripheral neutrophil count, fibrinogen, C-reactive protein and serum IL-6, suggesting a greater proinflammatory effect among obese compared with non-obese participants (table 3). Obesity status modified the effect of indoor PM2.5-10 on peripheral neutrophil count, peripheral eosinophil count and exhaled nitric oxide, an indicator of airway inflammation, suggesting that obese individuals have an enhanced pulmonary and systemic inflammatory response to indoor PM2.5-10 compared with non-obese individuals. The association between PM and IL-8, tumour necrosis factor- $\alpha$ and interferon- $\gamma$ did not differ by obesity status.

\section{Discussion}

In a study of individuals with moderate-to-severe COPD, we found evidence that obesity modifies the effect of exposure to indoor PM on COPD outcomes, including respiratory symptoms, rescue medication use, and airway and systemic markers of inflammation. These findings extend the emerging evidence that obesity may increase susceptibility to particulate air pollution and address a critical gap in understanding this relationship in COPD. As obesity has become epidemic, these findings have public health implications worldwide, both in terms of defining acceptable air quality standards and identifying interventions at the individual level to mitigate health risks.

Our findings in a study population with COPD are consistent with a growing body of work suggesting that being overweight or obese increases susceptibility to air pollution among individuals with asthma. In a longitudinal cohort study of inner-city children with asthma, indoor PM2.5 was associated with increased asthma symptoms and the asthmatic response to PM2.5 was much greater in overweight and obese children [15]. This observation was corroborated in an epidemiological study of 30000 children in China, which demonstrated that overweight and obese children had more prevalent asthma and more respiratory 


\section{TABLE 1 Baseline participant characteristics by weight status}

\begin{tabular}{|c|c|c|c|}
\hline & Non-obese & Obese & p-value \\
\hline Subjects $\mathrm{n}$ & 37 & 47 & \\
\hline Age years & $70.0 \pm 7.9$ & $68.1 \pm 6.9$ & 0.23 \\
\hline Male sex & 57 & 60 & 0.80 \\
\hline \multicolumn{4}{|l|}{ Race } \\
\hline Caucasian & 92 & 85 & \multirow[t]{3}{*}{0.40} \\
\hline Black/African American & 8 & 11 & \\
\hline Other & 0 & 4 & \\
\hline \multicolumn{4}{|l|}{ Education } \\
\hline Less than high school & 16 & 23 & \multirow[t]{5}{*}{0.19} \\
\hline High school & 19 & 21 & \\
\hline Some college & 38 & 28 & \\
\hline Bachelor's degree & 16 & 9 & \\
\hline At least some graduate school & 11 & 19 & \\
\hline Smoking history pack-years & $65 \pm 32$ & $50 \pm 24$ & 0.02 \\
\hline FEV $1 \%$ predicted & $51 \pm 18$ & $55 \pm 16$ & 0.30 \\
\hline Body mass index $\mathrm{kg} \cdot \mathrm{m}^{-2}$ & $25 \pm 3$ & $35 \pm 4$ & 0.00 \\
\hline Atopic & 22 & 36 & 0.17 \\
\hline \multicolumn{4}{|l|}{ Disease severity (GOLD stage) } \\
\hline II & 35 & 53 & \multirow[t]{3}{*}{0.07} \\
\hline III & 43 & 40 & \\
\hline IV & 22 & 6 & \\
\hline \multicolumn{4}{|l|}{ Respiratory health status } \\
\hline Chronic bronchitis reported in ATS-DLD & 41 & 40 & 0.99 \\
\hline Emphysema reported in ATS-DLD & 73 & 55 & 0.10 \\
\hline $\mathrm{SGRQ}^{\#}$ & $35 \pm 17$ & $43 \pm 18$ & 0.03 \\
\hline mMRC & $2.4 \pm 1.0$ & $2.6 \pm 1.2$ & 0.28 \\
\hline Nocturnal symptoms & 14 & 36 & 0.02 \\
\hline ED/hospitalisation within past year & 14 & 23 & 0.25 \\
\hline \multicolumn{4}{|l|}{ Serum biomarkers } \\
\hline White blood cell count cells. $\mathrm{mm}^{-3}$ & $7891 \pm 2532$ & $7326 \pm 2229$ & 0.29 \\
\hline Neutrophil count cells $\cdot \mathrm{mm}^{-3}$ & $4890 \pm 2008$ & $4226 \pm 1449$ & 0.09 \\
\hline Eosinophil count cells $\mathrm{mm}^{-3}$ & $2.5 \pm 1.6$ & $3.2 \pm 2.4$ & 0.16 \\
\hline Fibrinogen $\mathrm{mg} \cdot \mathrm{dL}^{-1}$ & $437 \pm 88$ & $444 \pm 116$ & 0.79 \\
\hline C-reactive protein $\mathrm{ng} \cdot \mathrm{mL}^{-1}$ & $4.6 \pm 4.9$ & $7.6 \pm 18.6$ & 0.34 \\
\hline $\mathrm{IL}-6 \mathrm{pg} \cdot \mathrm{mL}^{-1}$ & $2.3 \pm 2.7$ & $2.5 \pm 3.0$ & 0.73 \\
\hline $\mathrm{LL}-8 \mathrm{pg} \cdot \mathrm{mL}^{-1}$ & $8.7 \pm 3.4$ & $10.3 \pm 6.5$ & 0.18 \\
\hline Exhaled nitric oxide & $15.3 \pm 11.3$ & $20.7 \pm 13.4$ & 0.06 \\
\hline \multicolumn{4}{|l|}{ Comorbidities } \\
\hline Diabetes mellitus & 11 & 30 & 0.04 \\
\hline Obstructive sleep apnoea & 16 & 32 & 0.10 \\
\hline Myocardial infarction & 5 & 19 & 0.06 \\
\hline Stroke & 8 & 13 & 0.49 \\
\hline Congestive heart failure & 3 & 9 & 0.26 \\
\hline \multicolumn{4}{|l|}{ Baseline medication use } \\
\hline Short-acting $\beta$-agonist & 43 & 49 & 0.60 \\
\hline LABA & 6 & 6 & 0.88 \\
\hline ICS & 11 & 17 & 0.40 \\
\hline ICS/LABA & 49 & 51 & 0.83 \\
\hline Anticholinergic & 51 & 47 & 0.68 \\
\hline \multicolumn{4}{|l|}{ Environmental characteristics } \\
\hline Indoor $\mathrm{PM} 2.5 \mu \mathrm{g} \cdot \mathrm{m}^{-3}$ & $8.0(4.3-15.1)$ & $9.1(5.4-14.9)$ & 0.48 \\
\hline Indoor PM2.5-10 $\mu \mathrm{g} \cdot \mathrm{m}^{-3}$ & $4.2(2.9-6.8)$ & $4.6(3.3-7.2)$ & 0.52 \\
\hline Time spent indoors $\mathrm{h}$ & $22.1 \pm 0.2$ & $21.8 \pm 0.2$ & 0.27 \\
\hline
\end{tabular}

Data are presented as mean $\pm S D, \%$ or median (interquartile range), unless otherwise stated. $N=84$. $F E V$ 1: forced expiratory volume in $1 \mathrm{~s}$; GOLD: Global Initiative for Chronic Obstructive Lung Disease; ATS-DLD: American Thoracic Society-Division of Lung Disease questionnaire; SGRQ: St George's Respiratory Questionnaire; mMRC: modified Medical Research Council; ED: emergency department; IL: interleukin; LABA: long-acting $\beta$-agonist; ICS: inhaled corticosteroid; PM2.5: particulate matter with an aerodynamic size $\leqslant 2.5 \mu \mathrm{m}$; PM2.5-10: particulate matter with an aerodynamic size $2.5-10 \mu \mathrm{m}$. \#: scale 0-100, higher score indicates more limitations; ${ }^{\text {ๆ: }}$ scale $0-4$; higher score indicates more dyspnoea. 
TABLE 2 Associations between indoor particulate matter concentration and chronic obstructive pulmonary disease health outcomes by weight

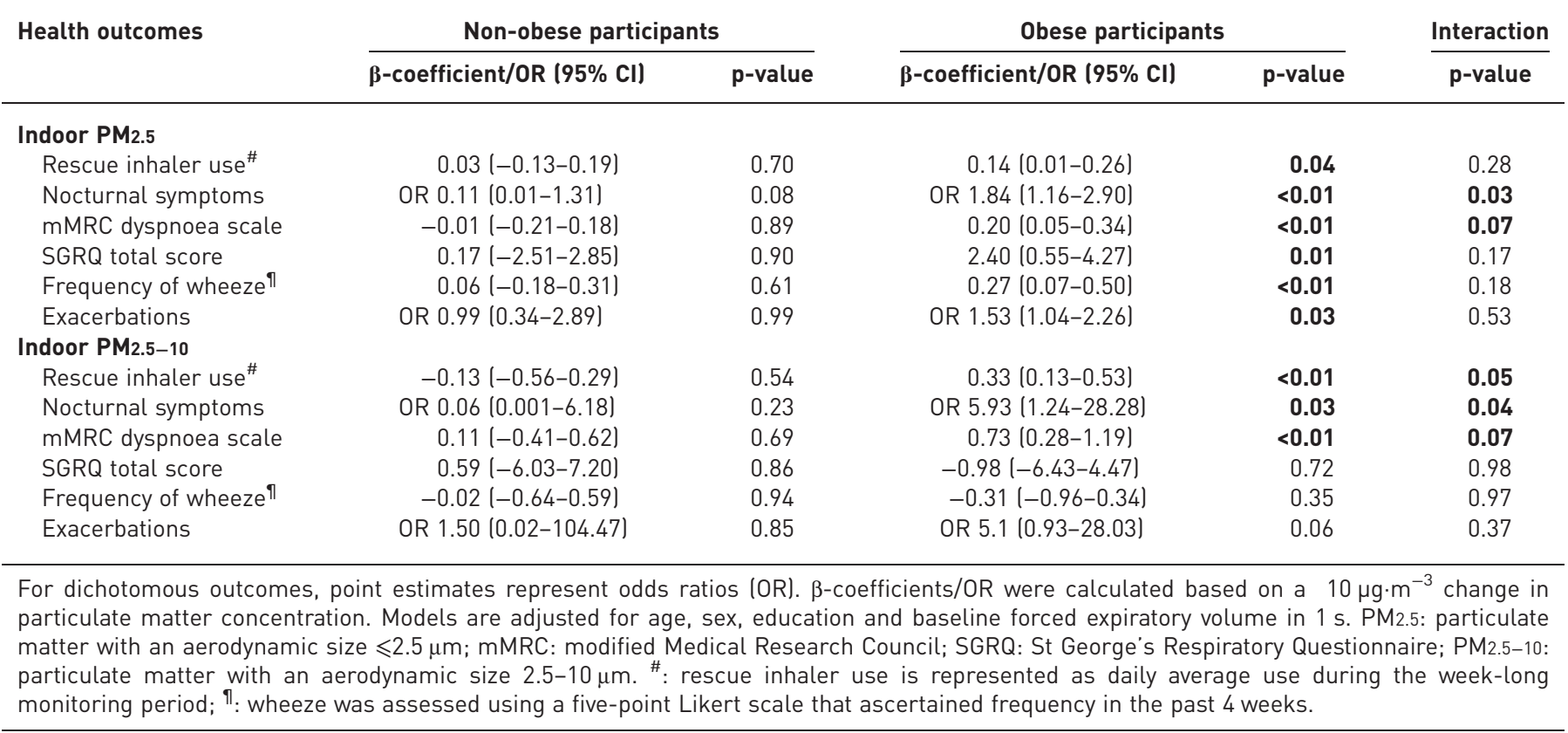

symptoms in response to air pollution compared with normal weight children [13]. An urban cohort of young children with asthma demonstrated that obese children were more likely to develop asthma in association with greater exposure to polycyclic aromatic hydrocarbons than non-obese children [34]. A study of 104 older adults with asthma also investigated traffic-related pollution and found that a strong detrimental effect was limited to the $42 \%$ of the cohort with BMI $>30 \mathrm{~kg} \cdot \mathrm{m}^{-2}$ [14].

In addition to studies in asthma, there have been a few conflicting studies investigating obesity as a modifier of associations with air pollutants in general populations. In a study of elderly men in the USA, ozone was associated with a greater decline in lung function among obese compared with non-obese participants [35]. By contrast, in a population-based study of Swiss adults (SAPALDIA), the investigators reported that the beneficial effects of improved air quality on the rate of decline in lung function were greatest for normal and underweight persons [36]. However, among the subgroup with asthma, the beneficial effects of improvements in air quality tended to be greatest among obese persons. In an experimental study that investigated the role of BMI on response to ozone exposure, increasing BMI was associated with greater pulmonary function impairment in response to ozone and this was most prominent among women [37]. In the present study, participants with COPD were followed for 6 months and indoor PM exposure was associated with an accentuated clinical response among obese individuals, manifested as increases in symptoms and rescue medication use.

The increases in systemic and pulmonary inflammation support our findings of increases in clinical symptoms in response to PM among obese compared with non-obese individuals. The biomarkers in the present study were chosen a priori based on previous studies that have reported increases in systemic inflammation in response to ambient PM exposure [38]. As obesity is a proinflammatory state, it is possible that obesity predisposes to a heightened inflammatory response and that, when both conditions are present, there is a multiplicative effect [39]. This is suggested by our findings of greater increases in IL-6, C-reactive protein, fibrinogen and neutrophil count in response to indoor PM exposure among obese compared with non-obese individuals, and also by animal models. For example, studies have shown that obese mice exhibit enhanced pulmonary inflammation (greater IL-6) in response to ozone compared with non-obese mice $[40,41]$. It is perhaps surprising that PM would lead to a greater increase in peripheral eosinophils, as well as neutrophils, among the obese. The results for PM2.5-10 suggested an enhanced pulmonary and systemic eosinophilic response among obese compared with non-obese individuals. While two previous studies have described a positive association between air pollution exposure and exhaled nitric oxide concentrations in healthy volunteers [42,43], obesity and exhaled nitric oxide concentrations have been negatively correlated in studies of asthma and have not been thoroughly investigated in individuals with COPD. While it is possible that atopic status or allergen content of the PM may be 

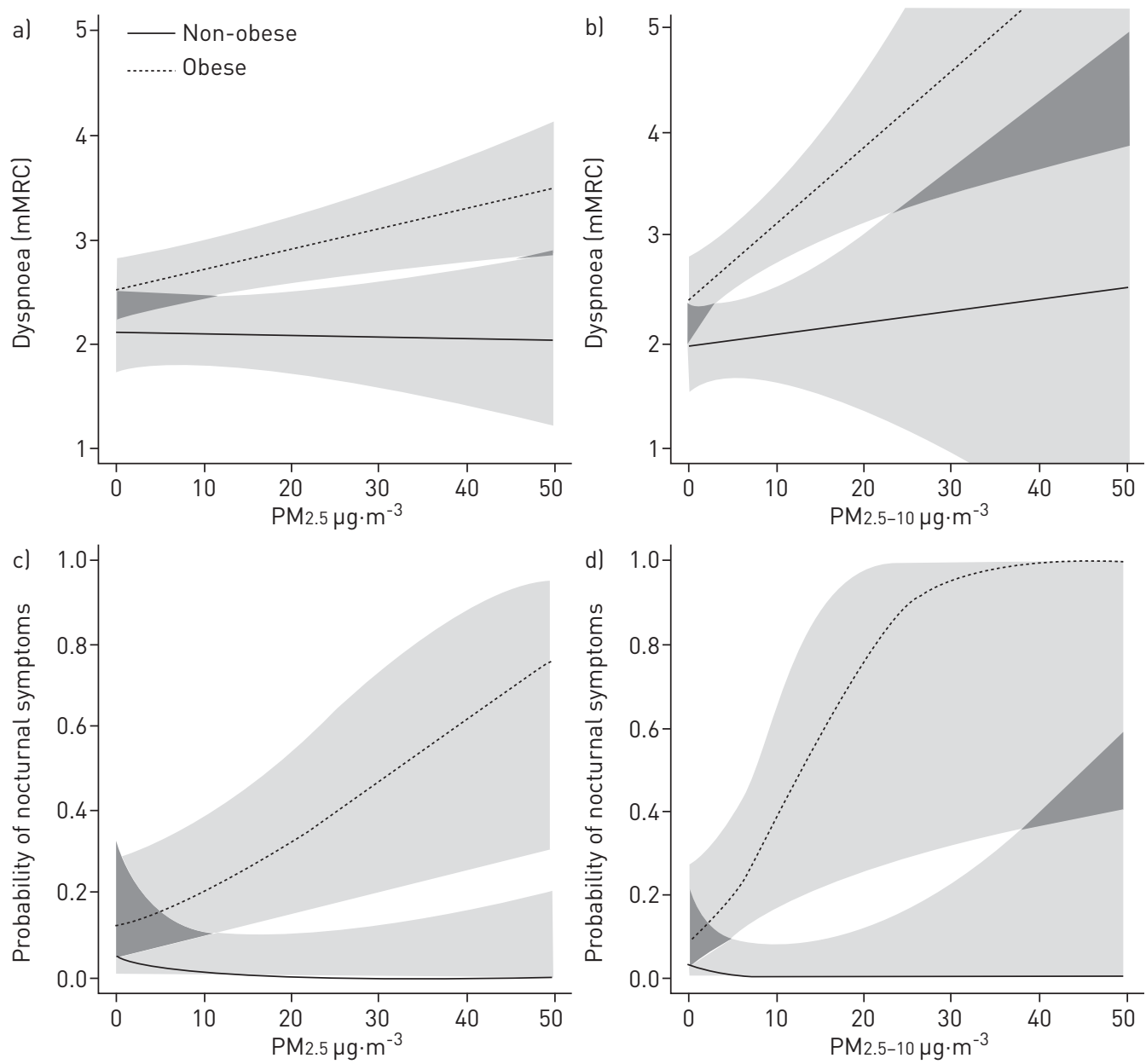

FIGURE 1 The relationship between particulate matter and symptoms by obesity status. The dashed lines depict obese individuals and the solid lines depict non-obese individuals. a) and b) demonstrate the relationship between particulate matter with an aerodynamic size $\leqslant 2.5 \mu \mathrm{m}$ (PM2.5) and particulate matter with an aerodynamic size $2.5-10 \mu \mathrm{m}$ (PM2.5-10) and dyspnoea as assessed by the modified Medical Research Council (mMRC) questionnaire, respectively. c) and d) demonstrate the relationship between $\mathrm{PM}_{2.5}$ and PM2.5-10 and the probability of reporting nocturnal symptoms of wheeze, respectively.

influencing this relationship, we did not find evidence that atopy mediated the relationship when atopic status was added to the multivariate models.

Additional factors that may be implicated in differential susceptibility to air pollution between obese and non-obese individuals include adipokines, oxidative stress and impaired glucocorticoid response. Hormones of obesity, including adipokines, leptin and resistin, may be implicated in the mechanism for accentuated PM effects among obese individuals. Prior studies suggest that increasing BMI is associated with increases in airways oxidative stress $[44,45]$. Studies in asthma have suggested that obesity may result in an impaired glucocorticoid response and that inhaled corticosteroid use may play a protective role in modifying PM respiratory effects [46-48]. Thus, it is possible that obese asthmatics taking inhaled corticosteroids may not be protected from harmful PM effects to the same extent as their non-obese counterparts due to corticosteroid resistance. The role of glucocorticoid responsiveness in influencing PM respiratory effects in COPD remains unknown, but may be another means by which obesity modifies susceptibility to particulate pollution exposure.

Changes in respiratory physiology that occur with obesity may be another mechanism by which obesity enhances susceptibility to PM. It is possible that obese individuals have increases in particle deposition, or changes in particle deposition patterns, compared with non-obese individuals [49]. Previous studies, including a particle deposition study in children and a weight loss trial in adults, have suggested an association between obesity and increases in tidal volume, which may results in a greater dose of inhaled particles among those that are obese $[50,51]$. Another possibility is that increases in pulmonary blood volumes from obesity increase the proinflammatory potential of the smallest particles of PM that are 
TABLE 3 Associations between indoor particulate matter concentration and markers of inflammation by obesity status

\begin{tabular}{|c|c|c|c|c|c|}
\hline Biomarkers & \multicolumn{2}{|c|}{ Non-obese participants } & \multicolumn{2}{|c|}{ Obese participants } & Interactior \\
\hline \multicolumn{6}{|l|}{ Indoor PM2.5 } \\
\hline Neutrophil count cells $\mathrm{mm}^{-3}$ & $-249(-608-110)$ & 0.17 & $87.8(-115-291)$ & 0.40 & 0.04 \\
\hline Eosinophil count cells $\cdot \mathrm{mm}^{-3}$ & $4.80(-18.9-28.5)$ & 0.69 & $36.7(14.1-59.3)$ & $<0.01$ & 0.07 \\
\hline Fibrinogen $\mathrm{mg} \cdot \mathrm{dL}^{-1}$ & $-10.5(-29.0-8.01)$ & 0.27 & $11.98(-1.86-25.8)$ & 0.09 & 0.08 \\
\hline Serum IL- $8^{\#} \mathrm{pg} \cdot \mathrm{mL}^{-1}$ & $0.06(-0.03-0.16)$ & 0.17 & $0.03(-0.05-0.10)$ & 0.49 & 0.52 \\
\hline $\mathrm{TNF}-\alpha^{\#} \mathrm{pg} \cdot \mathrm{mL}^{-1}$ & $0.04(-0.02-0.10)$ & 0.27 & $-0.02(-0.10-0.07)$ & 0.72 & 0.33 \\
\hline Interferon- $\gamma^{\#} \mathrm{pg} \cdot \mathrm{mL}^{-1}$ & $0.13(-0.11-0.38)$ & 0.30 & $0.11(-0.06-0.28)$ & 0.21 & 0.75 \\
\hline Exhaled nitric oxide ${ }^{\#} \mathrm{ppb}$ & $-0.04(-0.17-0.10)$ & 0.59 & $0.02(-0.08-0.11)$ & 0.73 & 0.59 \\
\hline \multicolumn{6}{|l|}{ Indoor PM2.5-10 } \\
\hline Peripheral WBC count cells. $\mathrm{mm}^{-3}$ & $-577.5(-1747-592.6)$ & 0.33 & $-477.6(-1501-546.3)$ & 0.36 & 0.42 \\
\hline Serum IL-6 ${ }^{\#} \mathrm{pg} \cdot \mathrm{mL}^{-1}$ & $-0.12(-0.44-0.20)$ & 0.45 & $0.08(-0.24-0.41)$ & 0.61 & 0.39 \\
\hline Serum IL-8 ${ }^{\#} \mathrm{pg} \cdot \mathrm{mL}^{-1}$ & $0.13(-0.07-0.33)$ & 0.21 & $0.04(-0.17-0.25)$ & 0.72 & 0.63 \\
\hline $\mathrm{TNF}-\alpha^{\#} \mathrm{pg} \cdot \mathrm{mL}^{-1}$ & $0.04(-0.10-0.17)$ & 0.61 & $-0.01(-0.24-0.23)$ & 0.95 & 0.25 \\
\hline Interferon- $\gamma^{\#} \mathrm{pg} \cdot \mathrm{mL}^{-1}$ & $-0.04(-0.66-0.59)$ & 0.91 & $0.23(-0.33-0.78)$ & 0.42 & 0.64 \\
\hline Exhaled nitric oxide ${ }^{\#} \mathrm{ppb}$ & $-0.21(-0.57-0.15)$ & 0.25 & $0.34(-0.06-0.73)$ & 0.09 & 0.05 \\
\hline \multicolumn{6}{|c|}{$\begin{array}{l}\beta \text {-coefficients/OR were calculated based on a } 10 \mu \mathrm{g} \cdot \mathrm{m}^{-3} \text { change in particulate matter concentration. Models are adjusted for age, sex, } \\
\text { education and baseline forced expiratory volume in } 1 \mathrm{~s} \text {. PM2.5: particulate matter with an aerodynamic size } \leqslant 2.5 \mu \mathrm{m} \text {; WBC: white blood cell; IL: } \\
\text { interleukin; TNF: tumour necrosis factor; PM2.5-10: particulate matter with an aerodynamic size } 2.5-10 \mu \mathrm{m} \text {. \#: outcomes that have been log } \\
\text { transformed. }\end{array}$} \\
\hline
\end{tabular}

capable of translocating the alveolar-capillary barrier. In this way, similar to the mechanism by which diffusing capacity of the lung for carbon monoxide may increase in obesity due to increases in pulmonary blood volume [52], particle exposure may be increased with obesity. This would probably have greater implications for respiratory effects of fine PM as only these smaller particles are capable of reaching the distal airways and alveolar-capillary interfaces.

As COPD affects individuals that frequently have comorbid medical conditions, these warrant consideration. While comorbidities such as gastro-oesophageal reflux disease and deconditioning may be more prevalent among obese individuals and may contribute to increased symptoms among obese individuals with COPD, this would be unlikely to account for the increased effect of PM exposure on obese individuals with COPD. It is possible that sleep disordered breathing, which is more common among obese individuals, increases susceptibility to air pollution due to changes in breathing patterns or particle deposition. Polysomnograms were not included as part of our study protocol and while self-report of sleep apnoea was available, sample size precluded us from drawing conclusions about the role of sleep apnoea in mediating susceptibility. The role of concomitant cardiac conditions would be more likely to influence the differential effects of PM among obese and non-obese individuals with COPD. PM exposure impacts cardiac function, obesity is a risk factor for cardiovascular disease, and cardiovascular disease is a major source of morbidity and mortality for patients with COPD. Furthermore, recent studies suggest that obesity may confer increased susceptibility to cardiac risks of PM exposure [53-56]. While our study was not designed to address cardiac outcomes and the sample size is too small to comprehensively study the role of cardiac co-morbidities, this would also be of interest in future studies.

It is notable that despite the modest sample size in our study, there was detectable effect modification for several of the respiratory outcomes. While the associations between indoor PM and several outcomes (inhaler use, nocturnal symptoms and dyspnoea) reflected acute effects, the time-scale for other outcomes (health status (SGRQ), wheeze and exacerbations) reflected short-term effects between 1 and 3 months. To assess these relationships, it was assumed that exposures captured during the 1-week monitoring period were reflective of the recent past. While this increases the possibility of reverse causality, the consistency of the findings suggests that short-term effects of indoor PM exposure may have a greater impact on obese versus non-obese individuals with COPD. While it is possible that pollen count or influenza prevalence are 
potential confounders, data on these exposures were not available for inclusion in the analyses. The present study did not include radiographic imaging to provide radiographic characterisation of emphysema and airways, which would be of interest in future studies. The generalisability of our findings was limited due to a sample comprised predominantly of older white males, which underscores the need for larger studies that include greater representation of women and diverse ethnic backgrounds. However, a strength of the present study is the detailed characterisation and repeated assessment of each participant's home exposures and respiratory status.

\section{Summary}

In a study of individuals with moderate-to-severe COPD, obesity modified the effect of indoor PM exposure on respiratory outcomes. Indoor PM2.5 and PM2.5-10 were associated with greater increases in symptoms and rescue medication use among obese individuals compared with non-obese individuals with COPD, and differences in inflammatory responses support the accentuated response to particulate pollution among the obese. These findings suggest that obesity may confer increased susceptibility to fine particulate pollution exposure in COPD and underscore the need for future studies defining the mechanisms by which this may occur.

\section{References}

1 World Health Organization. The global burden of disease: 2004 update. Geneva, WHO Press, 2008.

2 Salvi S. Tobacco smoking and environmental risk factors for chronic obstructive pulmonary disease. Clin Chest Med 2014; 35: 17-27.

3 Dominici F, Peng RD, Bell ML, et al. Fine particulate air pollution and hospital admission for cardiovascular and respiratory diseases. JAMA 2006; 295: 1127-1134.

4 Peacock JL, Anderson HR, Bremner SA, et al. Outdoor air pollution and respiratory health in patients with COPD. Thorax 2011; 66: 591-596.

5 McCormack MC, Breysse PN, Hansel NN, et al. Common household activities are associated with elevated particulate matter concentrations in bedrooms of inner-city Baltimore pre-school children. Environ Res 2008; 106: $148-155$.

6 Klepeis NE, Nelson WC, Ott WR, et al. The National Human Activity Pattern Survey (NHAPS): a resource for assessing exposure to environmental pollutants. J Expo Anal Environ Epidemiol 2001; 11: 231-252.

7 Hansel NN, McCormack MC, Belli AJ, et al. In-home air pollution is linked to respiratory morbidity in former smokers with chronic obstructive pulmonary disease. Am J Respir Crit Care Med 2013; 187: 1085-1090.

8 Landbo C, Prescott E, Lange $\mathrm{P}$, et al. Prognostic value of nutritional status in chronic obstructive pulmonary disease. Am J Respir Crit Care Med 1999; 160: 1856-1861.

9 Flegal KM, Carroll MD, Ogden CL, et al. Prevalence and trends in obesity among US adults, 1999-2008. JAMA 2010; 303: 235-241.

10 Cazzola M, Calzetta L, Lauro D, et al. Asthma and COPD in an Italian adult population: role of BMI considering the smoking habit. Respir Med 2013; 107: 1417-1422.

11 Montes de Oca M, Tálamo C, Perez-Padilla R, et al. Chronic obstructive pulmonary disease and body mass index in five Latin America cities: the PLATINO study. Respir Med 2008; 102: 642-650.

12 Putcha N, Puhan MA, Hansel NN, et al. Impact of co-morbidities on self-rated health in self-reported COPD: an analysis of NHANES 2001-2008. COPD 2013; 10: 324-332.

13 Dong GH, Qian Z, Liu MM, et al. Obesity enhanced respiratory health effects of ambient air pollution in Chinese children: the Seven Northeastern Cities study. Int J Obes (Lond) 2013; 37: 94-100.

14 Epstein TG, Ryan PH, LeMasters GK, et al. Poor asthma control and exposure to traffic pollutants and obesity in older adults. Ann Allergy Asthma Immunol 2012; 108: 423-428.

$15 \mathrm{Lu} \mathrm{KD}$, Breysse PN, Diette GB, et al. Being overweight increases susceptibility to indoor pollutants among urban children with asthma. J Allergy Clin Immunol 2013; 131: 1017-1023.

16 Vibhuti A, Arif E, Deepak D, et al. Correlation of oxidative status with BMI and lung function in COPD. Clin Biochem 2007; 40: 958-963.

17 De S. Body mass index among patient with chronic obstructive pulmonary diseases. Indian J Physiol Pharmacol 2012; 56: 353-358.

18 Celli BR, Cote CG, Marin JM, et al. The body-mass index, airflow obstruction, dyspnea, and exercise capacity index in chronic obstructive pulmonary disease. N Engl J Med 2004; 350: 1005-1012.

19 Middleton ET, Morice AH. Breath carbon monoxide as an indication of smoking habit. Chest 2000; 117: 758-763.

20 McCormack MC, Breysse PN, Matsui EC, et al. In-home particle concentrations and childhood asthma morbidity. Environ Health Perspect 2009; 117: 294-298.

21 Hankinson JL, Odencrantz JR, Fedan KB. Spirometric reference values from a sample of the general U.S. population. Am J Respir Crit Care Med 1999; 159: 179-187.

22 Miller MR, Hankinson J, Brusasco V, et al. Standardisation of spirometry. Eur Respir J 2005; 26: 319-338.

23 Global Initiative for Chronic Obstructive Lung Disease. Global strategy for the diagnosis, management, and prevention of COPD (Updated 2010). www.goldcopd.com Date last updated: January 2014. Date last accessed: 2012.

24 World Health Organization. WHO Overweight and obesity. Fact sheet No. 311. www.who.int/mediacentre/ factsheets/fs311/en/index.html Date last updated: August, 2014. Date last accessed February 12, 2014.

25 Clinical guidelines on the identification, evaluation, and treatment of overweight and obesity in adults: executive summary. Expert Panel on the Identification, Evaluation, and Treatment of Overweight in Adults. Am J Clin Nutr 1998; 68: 899-917.

26 Bestall JC, Paul EA, Garrod R, et al. Usefulness of the Medical Research Council (MRC) dyspnoea scale as a measure of disability in patients with chronic obstructive pulmonary disease. Thorax 1999; 54: 581-586. 

Respiratory Questionnaire. Clin Ther 2000; 22: 1121-1145.

28 Han MK, Kazerooni EA, Lynch DA, et al. Chronic obstructive pulmonary disease exacerbations in the COPDGene study: associated radiologic phenotypes. Radiology 2011; 261: 274-282.

29 Ferris BG. Epidemiology Standardization Project (American Thoracic Society). Am Rev Respir Dis 1978; 118: $1-120$.

30 American Thoracic Society, European Respiratory Society. ATS/ERS recommendations for standardized procedures for the online and offline measurement of exhaled lower respiratory nitric oxide and nasal nitric oxide, 2005. Am J Respir Crit Care Med 2005; 171: 912-930.

31 Diggle PJ, Heagerty P, Liang KY, et al. The analysis of Longitudinal Data. 2nd Edn. Oxford, Oxford University Press, 2002.

32 Matsui EC, Hansel NN, Aloe C, et al. Indoor pollutant exposures modify the effect of airborne endotoxin on asthma in urban children. Am J Respir Crit Care Med 2013; 188: 1210-1215.

33 Selvin S. Statistical analysis of epidemiologic data. New York, Oxford University Press, 1996.

34 Jung KH, Perzanowski M, Rundle A, et al. Polycyclic aromatic hydrocarbon exposure, obesity and childhood asthma in an urban cohort. Environ Res 2014; 128: 35-41.

35 Alexeeff SE, Litonjua AA, Suh H, et al. Ozone exposure and lung function: effect modified by obesity and airways hyperresponsiveness in the VA normative aging study. Chest 2007; 132: 1890-1897.

36 Schikowski T, Schaffner E, Meier F, et al. Improved air quality and attenuated lung function decline: modification by obesity in the SAPALDIA cohort. Environ Health Perspect 2013; 121: 1034-1039.

37 Bennett WD, Hazucha MJ, Folinsbee LJ, et al. Acute pulmonary function response to ozone in young adults as a function of body mass index. Inhal Toxicol 2007; 19: 1147-1154.

38 Brook RD, Rajagopalan S, Pope CA 3rd et al. Particulate matter air pollution and cardiovascular disease: an update to the scientific statement from the American Heart Association. Circulation 2010; 121: 2331-2378.

39 Dubowsky SD, Suh H, Schwartz J, et al. Diabetes, obesity, and hypertension may enhance associations between air pollution and markers of systemic inflammation. Environ Health Perspect 2006; 114: 992-998.

40 Johnston RA, Theman TA, Lu FL, et al. Diet-induced obesity causes innate airway hyperresponsiveness to methacholine and enhances ozone-induced pulmonary inflammation. J Appl Physiol 2008; 104: 1727-1735.

41 Lu FL, Johnston RA, Flynt L, et al. Increased pulmonary responses to acute ozone exposure in obese $\mathrm{db} / \mathrm{db} \mathrm{mice}$. Am J Physiol Lung Cell Mol Physiol 2006; 290: L856-L865.

42 Adamkiewicz G, Ebelt S, Syring M, et al. Association between air pollution exposure and exhaled nitric oxide in an elderly population. Thorax 2004; 59: 204-209.

43 Ghio AJ, Kim C, Devlin RB. Concentrated ambient air particles induce mild pulmonary inflammation in healthy human volunteers. Am J Respir Crit Care Med 2000; 162: 981-988.

44 Holguin F. Oxidative stress in airways diseases. Ann Am Thorac Soc 2013; 10: Suppl., S150-S157.

45 Vincent $\mathrm{HK}$, Innes $\mathrm{KE}$, Vincent KR. Oxidative stress and potential interventions to reduce oxidative stress in overweight and obesity. Diabetes Obes Metab 2007; 9: 813-839.

46 Sutherland ER, Goleva E, Strand M, et al. Body mass and glucocorticoid response in asthma. Am J Respir Crit Care Med 2008; 178: 682-687.

47 Peters-Golden M, Swern A, Bird SS, et al. Influence of body mass index on the response to asthma controller agents. Eur Respir J 2006; 27: 495-503.

48 Fernandez-Boyanapalli R, Goleva E, Kolakowski C, et al. Obesity impairs apoptotic cell clearance in asthma J Allergy Clin Immunol 2013; 131: 1041-1047.

49 Graham DR, Chamberlain MJ, Hutton L, et al. Inhaled particle deposition and body habitus. Br J Ind Med 1990; 47: 38-43.

50 Bennett WD, Zeman KL. Effect of body size on breathing pattern and fine-particle deposition in children. J Appl Physiol 2004; 97: 821-826.

51 Matos CM, Moraes KS, França DC, et al. Changes in breathing pattern and thoracoabdominal motion after bariatric surgery: a longitudinal study. Respir Physiol Neurobiol 2012; 181: 143-147.

52 Ray CS, Sue DY, Bray G, et al. Effects of obesity on respiratory function. Am Rev Respir Dis 1983; 128: 501-506.

53 Chen JC, Cavallari JM, Stone PH, et al. Obesity is a modifier of autonomic cardiac responses to fine metal particulates. Environ Health Perspect 2007; 115: 1002-1006.

54 Huang W, Zhu T, Pan X, et al. Air pollution and autonomic and vascular dysfunction in patients with cardiovascular disease: interactions of systemic inflammation, overweight, and gender. Am J Epidemiol 2012; 176: $117-126$.

55 Kannan S, Dvonch JT, Schulz AJ, et al. Exposure to fine particulate matter and acute effects on blood pressure: effect modification by measures of obesity and location. J Epidemiol Community Health 2010; 64: 68-74.

56 Miller KA, Siscovick DS, Sheppard L, et al. Long-term exposure to air pollution and incidence of cardiovascular events in women. N Engl J Med 2007; 356: 447-458. 